\title{
TOWARD A BETTER UNDERSTANDING OF CROWDED AND SCARCE SPORTING EVENTS: DO FANS THINK AS MUCH AS THEY FEEL?
}

\author{
Frank Pons, Université Laval, Canada et Euromed Management, France. \\ Mehdi Mourali, University of Calgary, Canada. \\ Lionel Maltese, Eurimed Management. \\ André Richelieu, Université Laval, Canada.
}

\begin{abstract}
Recent studies (Tombs and Mc Coll-Kennedy, 2003; Rosenbaum and Massaiah, 2007; Machleit et al., 2000, Eroglu, Machleit and Barr, 2005) underline the importance of considering different types of crowding (human versus spatial) when interpreting results on a crowd's impact. They also insist on the potential moderating role of the service encounter and the values at stake (leisure versus utilitarian) (Eroglu, Machleit and Barr, 2005).

One potential variable that has received limited attention from researchers (Tombs and Mc Coll-Kennedy, 2003) is the extent to which the experience represents a scarce event for the consumer (Superbowl, World cup soccer). For example, scarce sporting and cultural events seem to often be of greater value and to trigger more extreme behaviors from consumers (Madrigal, 2000; Holt, 1995).

Using an experimental design, this study demonstrates that scarcity adds value to the sporting event experience (Wann et al, 2004; Cialdini, 1995). Our study also offers potential explanations of the mechanisms behind the scarcity effect. These results suggest the importance of signals sent by the crowd to potential customers, particularly driving their expectations. Scarcity can be considered as one of these cues or signals, and future research along this line is critical in the sporting event business.
\end{abstract}

References available upon request 